\title{
Editorial
}

\section{Autores y autorías: Controversia más allá de la investigación}

Todo trabajo de investigación desde su concepción hasta su término, experimenta un torbellino emocional entre sus actores. Amor-/-odio... es como si la investigación fuera comparable con una tortuosa relación amorosa. Sus protagonistas se acercan buscando colaborar, motivados y con sueños de éxito. Sin embargo, a medida que las obligaciones se materializan, los problemas toman nombre y el tiempo se agota; la luna de miel que unió a personas "afines" parece acabar súbitamente. Los "matrimonios científicos" al igual que los reales, pueden superar las pruebas, o bien acabar en una separación irreconciliable. Para evitar y mitigar las crisis todo proyecto de investigación debe confiar en un líder; el cual no necesariamente contará con el mayor conocimiento 0 grado académico, pero que velará por la armonía y solidaridad del grupo. Este guía identifica potenciales problemas, y evita discusiones que desgastan el quehacer científico, concentrando al equipo en lo que realmente importa. Casi siempre será quien tomará las riendas de la publicación científica y la llevará a buen puerto. Aquel personaje de confianza y autoridad, luego lo conoceremos en las publicaciones como autor de correspondencia. Él conoce a profundidad el trabajo sometido a publicación, lo que hizo cada coautor y sus competencias para responder a revisores. Serán sus hombros los que lleven la mayor responsabilidad, deberá rendir cuentas al Editor en Jefe de la revista e informará los avances del proceso.

En un proyecto de investigación no todos serán autores. Muchos sugieren, evaluan un paciente, prepararan muestras 0 consiguen insumos... pero, ¿es esta participación suficiente para convertirse en autor de un artículo científico?, ¿en qué momento del proyecto debe incorporarse un autor? Las respuestas para estas preguntas son subjetivas. El International Committee of Medical Journals Editors (ICMJE) menciona que un autor es aquel que contribuye sustancialmente en la concepción o diseño de la obra; 0 la adquisición, análisis o interpretación de datos; que redacte el trabajo o lo revise críticamente; que apruebe la versión final; y que conozca los detalles de cada parte del trabajo para poder rendir cuentas en todo momento. Con estos cuatro requisitos, aquel que se considere autor se vuelve indispensable para la publicación. A pesar de no ser protagonista de todas las etapas, su aporte debe significar una pieza fundamental en la construcción del producto. Los autores de correspondencia decidirán quien no es autor, pero recibirá un agradecimiento, y negociará la posición de cada uno (primer autor, o último autor) según lo convengan los diferentes participantes.

Desafortunadamente, las publicaciones científicas no están exentas de cometer faltas a la ética relacionadas con la autoría. Pueden presentarse problemas como autoría fantasma (ausencia de autores que merecieron un lugar en la publicación) 0 autoría concedida (donde personajes no vinculados a la investigación logran un escaño simplemente por sus méritos o posición académica). Estos últimos incluso conocen el trabajo una vez publicado y divulgado. Aunque algunas de estas faltas difícilmente son identificadas por los comités Editoriales (pues son producto de negociaciones oscuras internas); tanto el ICMJE y por supuesto el Comité Editorial de la Revista Odovtos-International Journal of Dental Sciences, apoya y confía en las buenas prácticas en la ética de la publicación; y enfatiza el llamado a los autores de velar porque estas normas se respeten en todo momento, ya que solo así, los artículos publicados reconocerán el trabajo de aquellos que realmente lo merecen.

\section{Daniel Chavarria Bolaños DDS, MSc, PhD}

Profesor-Investigador Facultad de Odontología, Universidad de Costa Rica, Costa Rica. Tel: +(506)83916923. Email: daniel.chavarria@ucr.ac.cr / danielchava2@gmail.com PO BOX: 1493-3000. Heredia, Costa Rica.

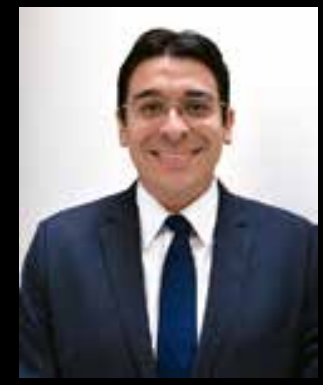

